\title{
Evaluation of Wild Segments Related to Growth Period Traits Using a Modified Wild Soybean (Glycine Soja Sieb. Et Zucc.) Chromosome Segment Substitution Line Population
}

He Qingyuan

Anhui Science and Technology University

Shihua Xiang

Zigong Academy of Agricultural Sciences

Huawei Yang

Zigong Academy of Agricultural Sciences

Wubin Wang

Nanjing Agricultural University

Yingjie Shu

Anhui Science and Technology University

Zhengpeng $\mathrm{Li}$

Anhui Science and Technology University

Songhua Wang ( $\sim$ Wangsh@ahstu.edu.cn )

Anhui Science and Technology University

Xiaoyan Yang

Anhui Science and Technology University

\section{Research Article}

Keywords: Soybean, Genome-wide association, 100-seed weight, protein content, oil content

Posted Date: May 7th, 2021

DOl: https://doi.org/10.21203/rs.3.rs-378074/v1

License: (c) (i) This work is licensed under a Creative Commons Attribution 4.0 International License. Read Full License 


\section{Abstract}

Soybean seeds contain high levels of oil and protein providing $69 \%$ and $57 \%$ of dietary protein and oil respectively. Although many quantitative trait loci for 100-seed weight (100SW), protein content (PRC) and oil content (OIC) have been reported, their genetic controls in soybeans remain unclear. The QTLallele constitution of three traits in the Sichuan and Chongqing eco-regions population (SCLBP) was studied using a representative sample composed of 228 accessions tested under four environments and analyzed based on 135 SSR and 107081 valid SNP (single nucleotide polymorphism linkage) markers. The varied range of 100SW, PRC and OIC of SCLBP were 4.82-33.35, 36.47-49.75 and 14.68-21.77 among accessions, respectively. The heritability $\left(h^{2}\right)$ and genetic coefficient of variation (GCV) of three traits were high. As a result, 26, 33 and 31 QTLs were found by SSR to be associated with 100SW, PRC and OIC, respectively. The allele of Sat_260 for 100SW was detected in 4 environments. In addition, 28, 198 and 250 loci for 100SW, PRC and OIC were found by SNP using mixed linear model (MLM), respectively. Further SNP haplotype analysis showed that 13, 35 and 60 blocks for 100SW, RPC and OIC were found. The block of Gm11_9895764-9917646 for 100SW was simultaneously detected in four environments. Among these QTLs, 1, 5, and 7 for 100SW, PRC and OIC were found by two methods of SSR and SNP at the same time. A majority of these QTLs overlapped with the previously reported loci. However, 9, 11 and 9 loci for 100SW, PRC and OIC using SSR and 3, 5 and 8 for 100SW, PRC and OIC haven't been reported using SNP in the study, respectively. Moreover, the genes of Glyma.11g130800, Glyma.13g217000 and Glyma.08g122600 were considered to be the most likely genes controlling $100 \mathrm{SW}$, PRC and OIC, respectively. Our findings provide evidence for mixed major plus polygenes inheritance for three traits and an extended understanding of their genetic architecture for molecular dissection and breeding utilization in soybeans.

\section{Introduction}

Soybean [Glycine $\max (\mathrm{L}$.$) ] is a major source of vegetable protein and oil providing approximately 69 \%$ and $57 \%$ of dietary protein and oil, respectively (USDA-FAS, http://www.fas.usda.gov/). Its seed is composed about $40 \%$ protein and $20 \%$ oil ( $\mathrm{Li}$ et al., 2019). Improving seed yield and quality is the major target for soybean breeders. Seed traits including 100-seed weight (100SW), protein content (PRC) and oil content (OIC) are important traits determining the yield and quality of soybean (Yang et al., 2019). 100seed weight is an important yield component of soybean and was generally positively correlated with seed yield (Burton et al. 1987a). Increases in seed oil and protein contents of soybean would improve the quality. Therefore, it is important way to improve soybean yield and quality by increasing 100SW, PRC and OIC of soybean (Han et al., 2012; Li et al., 2019). To dissect their genetic basis will help the improvement of yield and quality of soybean.

The 100SW, PRC and OIC are complex traits governed by multiple quantitative trait loci (QTLs) and influenced considerably by environments in soybeans. Hitherto, more than 304 QTL for 100 SW, 248 for PRC and 327 for OIC have been reported from 59, 58 and 34 bi-parental mapping populations, respectively, which were stored in Soybase (http://soybase.org; Diers et al., 1992; Mansur et al., 1996; 
Specht et al., 2001; Jun et al., 2008; Rossi et al., 2013; Akond, et al., 2014). However, the most locations of QTLs found in different studies often do not map to the same position. Only a few for 100SW, PRC and OIC have been confirmed or cloned (Lu et al., 2017; Fasoula et al., 2004; Wang et al., 2014). In addition, the limited recombination of bi-parent population or relatively low density of marker which hindered breeding efforts to improve seed traits through marker assisted selection (MAS).

In recent year, with the development of high density gene chip and re-sequencing, natural populations having more extensive recombination events in the evolutionary process of a natural population and shorter linkage disequilibrium (LD) blocks were used for mapping and wider phenotypic variation available through genome-wide association studies (GWAS) (Gupta et al., 2005). It has widely been applied to dissect the genetic basis for some complex traits in human (Pritchard and Przeworski, 2001; Jiang et al., 2013) and animal (Farnir et al., 2000; Miller et al., 2015). At present, association studies have also been used in many plants, such as Arabidopsis (Kim et al., 2007; Fulgione and Hancock, 2018), maize (Falke et al., 2007; Michael et al., 2009), rice (Yang et al., 2014; ), cotton (Li et al., 2016; Liu et al., 2018) and soybean (Zhang et al., 2015; Chang et al., 2018). However, how to break the negative correlation between oil and protein, breed soybean varieties having high PRC, OIC and 100SW has not been established in soybean. In order to better identify loci of high PRC, OIC and 100SW, and to service for breeding, high protein germplasm were used to dissect related genetic mechanism.

In the present study, GWAS analysis of soybean PRC, OIC and 100SW in Sichuan and Chongqing China based on 228 tested local and breeding varieties and 135 SSR markers and 107081 SNPs. Soybean of Sichuan and Chongqing are elite high protein germplasms (Yang and Zhou, 2020). The goal of this study is to identify QTLs associated with PRC, OIC and 100SW and to screen candidate genes located in peak marker regions. This study enhances our understanding of their genetic mechanisms of PRC, OIC and $100 S W$ in soybean. This study will lay a foundation for increasing soybean breeding efficiency of PRC, OIC and 100sW.

\section{Materials And Methods}

\section{Plant materials and field trials}

228 accessions including 206 landraces accessions and 22 bred varieties of spring (108) and summer (120) soybean were selected and collected from the Sichuan and Chongqing eco-regions population (SCLBP) to analyze the PRC, OIC and 100SW variation and for subsequent microarray typing. All experimental materials were planted at Fengyang (FY) $\left(32^{\circ} 47^{\prime} \mathrm{N}\right.$ and $\left.117^{\circ} 19^{\prime}\right)$ and Zigong (ZG) $\left(29^{\circ} 33^{\prime} \mathrm{N}\right.$ and $104^{\circ} 55^{\prime}$ ) Station in Anhui and Sichuan province, respectively, on June 19, 2016 and 2018, 2019. At each location, The population of SCLBP was planted in a randomized complete blocks experiment with 3 rows per plot, $2 \mathrm{~m}$ row length, 20 plants per row and $0.5 \mathrm{~m}$ row space and three replications. The four environments are coded as FY2016, ZG2016, FY2018 and ZG2019 respectively. The management of field was performed using conventional conditions. 


\section{Phenotypic evaluation and statistical analysis}

After the seeds were bulk-harvested and dried at each plot, the 100SW was determined in grams per 100 uniformly cleaned seeds. The PRC and OIC of seed were measured with about $20 \mathrm{~g}$ of seed by nearinfrared analysis instrument (Perten DA7200, Swedish).

The joint analysis of variance (ANOVA) was conducted for three traits using PROC GLM procedure of SAS 9.2 (SAS Institute, Cary, United States). The statistical model was $Y_{i j k}=\mu+G_{i}+E_{j}+(G L)_{i j}+\gamma_{k}+e$, where $\mu$ is the total mean, $G$ is the effect of the $i^{\text {th }}$ genotype, $E_{j}$ is the effect of the $j^{\text {th }}$ environment; $(G E)_{i j}$ is the genotype $\times$ environment interaction; $\gamma_{k}$ is the effect of $k^{\text {th }}$ replication; and $e$ is random error following $N(0$, $\left.\sigma_{\mathrm{e}}^{2}\right)$. The broad-sense heritability $\left(h^{2}\right)$ was estimated as: $h^{2}=\sigma_{\mathrm{g}}^{2} /\left[\sigma_{\mathrm{g}}^{2}+\left(\sigma_{\mathrm{ge}}^{2} / j\right)+\left(\sigma^{2} / r j\right)\right]$ for whole experiment and $h^{2}=\sigma_{\mathrm{g}}^{2} /\left[\sigma_{\mathrm{g}}^{2}+\sigma^{2} / \mathrm{r}\right.$ for an individual environment, where $\sigma_{\mathrm{g}}^{2}$ is the genotypic variance among accessions, $\sigma^{2}$ ge is the genotype $\times$ environment interaction variance, $\sigma^{2} / r \mathrm{j}$ is the error variance, $j, r$ are the numbers of environment and replications per environment, respectively. All parameters were estimated from the expected mean squares in the ANOVA.

\section{DNA extraction, SSR marker analysis, SNPs polymorphism, genotyping and haplotype block estimation}

Total DNA extracted from fresh leaves using the slightly modified CTAB method (Doyle and Doyle, 1984). A total of 135 simple sequence repeat (SSR) markers distributed basically evenly in Soymap2 (Song et al., 2004) were selected to genotype each accession. The reaction system and program of PCR were performed according to the method of $\mathrm{He}$ et al. (2015). The PCR products were detected on $8 \%$ polyacrylamide gels, and the fragments were visualized by sliver staining.

High-throughput SNPs were generated by illumina soybean 200K gene chip (Beijing Compass Biotechnology Co.). The internal reference quality control of SNP chip and methods of calling variation were based on according to chip operation manual (Illumina, 2012). A total of 107081 single nucleotide polymorphisms (SNPs) with low minor allele frequency (MAF) $\geq 1 \%$ and missing proportion $\leq 10 \%$ were used to genotype and further study in the 228 accessions. The genotype and SNP markers were established according to pLINK V2.0 software (Shaun, 2010). The haplotype blocks were divided by LD heatmap package of R project (Shin et al., 2006). The distribution of SNPs on chromosomes was displayed by Gapit software (version 3.0) (Tang et al., 2016).

\section{Linkage disequilibrium estimation}

Linkage disequilibrium (LD) between pair-wise SNPs was estimated by $r^{2}$ (the squared correlation between two loci) and $D^{\prime}$ (standardized disequilibrium coefficient) (Gaut and Long, 2003) using TASSEL5.2.59 software (Bradbury, 2007). In addition, LD ( $D^{\prime}$ and $r^{2}$ ) was estimated separately for all pairwise SNPs with a $100 \mathrm{~kb}$ summary bin setting within the $5 \mathrm{Mb}$ distance. The physical location of the euchromatin and heterochromatin region for each chromosome was defined as in the reference genome of G. max 2.0 (www.soybase.org). The LD decay was plotted as the physical distance versus $r^{2}$ with 
smooth curves fitted by locally weighted regression (LOESS) curves decayed to half its maximum value or to $r^{2}=0.2$ (Huang et al., 2010).

\section{Population structure and principal component analysis}

The kinship of accessions was calculated using Gapit software (version 3.0) with VanRaden program. The population structure was estimated by the software STRUCTURE 2.4.3 (Pritchard et al., 2000) using non-linkage SNPs. The number of subpopulations $(k)$ was set from 1 to 9 initially, with 5,000 burn-in period, 1000,000 Markov chain Monte Carlo (MCMC) method. Each Q matrix and the relevant P-value were obtained. The most likely number of subpopulations was selected according to the relationship between $k$ and $\Delta k$ (Evanno et al., 2005). Principal component analysis (PCA) was also performed by Gapit software to examine genetic structure and variation of different ecotype of soybean, and the first three eigenvectors were plotted in three dimensions. The cladogram was constructed using TASSEL V5.2.59 with neighbor joining method (Bradbury, 2007).

\section{Genome-wide association studies}

Associations mapping was performed by the TASSEL2.1 using SSR markers. The further GWAS was conducted by TASSEL5.2.59 with mixed linear model (MLM) using SNPs. To minimize false positives and increase result reliability, both population structure (PCA) and kinship $(K)$ matrix were applied for the population. The Bonferroni-corrected threshold of genome-wide significance was defined at 0.05 for the first stage, and 5 different threshold values were selected to converge in computing process for the second stage, respectively. QTLs were considered to exist at haplotype blocks where LOD score exceeded the corresponding significance threshold.

\section{Prediction of candidate genes}

The particular candidate genes were considered basing on the predictive genes source of Glyma 2.0 gene model. Their functions were predicated using protein-protein BLAST search tool of NCBI (http://blast.ncbi.nlm.nih.gov/Blast.cgi).

\section{Results}

\section{Phenotypic variation in the SCLBP}

The phenotypic characteristic of 100SW, PRC and OIC for SCLBP are showed in table 1. Averaged over four environments, 100SW, PRC and OIC showed a large variation with range values of 4.82-33.35 (g), $36.47-49.75 \%$ and $14.68-21.77 \%$, respectively. The ranges of absolute values of kurtosis and skewness were $0.11-1.58$ for 100SW, PRC and OIC, therefore, their distributions were approach to normal distributions. The heritability $\left(h^{2}\right)$ and genetic coefficient of variation (GCV) of 100SW were highest, secondly is OIC, the lowest is PRC. The variation distribution of three traits' phenotypic was showed in 
Fig. 1. The variance analysis showed that the 100SW, PRC and OIC were significantly affected by varieties, environments and reciprocity of varieties and environments (Table 2).

\section{GWAS analysis of 100SW, PRC and OIC using SSR}

Based on the MLM model of tassel2.1, the Q matrix of population structure was used as covariate, and to calculate the associate between phenotypic value of 100 SW, PRC and OIC and 135 pairs of SSR marker. A total of 26 SSR markers were associated with 100SW, 33 with PRC and 31 with OIC were detected in four environments. The allele of Sat_260 on chromosome 8 controlling 100SW was simultaneously detected in four environments. Two loci controlling 100SW were simultaneously detected in three environments, 6 loci controlling 100SW, 7 loci controlling PRC and 6 loci controlling OIC were simultaneously detected in two environments, respectively (Table S1).

\section{Distribution of SNPs and genetic characteristics of the mapping population}

A total of 159072 SNPs were initially identified in 238 accessions. 107081 valid SNPs were obtained and used for further analyses in 228 accessions after filtration according to the following criteria: (1) the minimum allele frequency (MAF) $\geq 0.01$, (2) sites with deletion ratio less than 0.10 , and (3) remove samples with high deletion ratio less than 0.10 , the average marker density of 1 SNP every $8.86 \mathrm{~kb}$ genome-wide, varying across chromosomes from $7.45 \mathrm{~kb}$ per SNP on chromosome 17 to $12.22 \mathrm{~kb}$ per SNP on chromosome 12 (Table S2). The MAF and haplotype block ( $>50 \mathrm{~kb}$ ) for the population characteristics are presented in Fig. 2. The population structure was analyzed using non-linkage 4792 SNP markers. The most likely K-value was determined 3 according to the relationship between K-value and $\triangle \mathrm{K}$-value (Fig. $3 \mathrm{~A}$ ), which suggested that the overall population could be divided into three subpopulations. The result was also supported by the phylogenetic analysis (Fig. 3B, C) and PCA (Fig. 3D). The LD decay rate of the population was estimated at $2000 \mathrm{~kb}$ in euchromatin, where $r^{2}$ dropped to half of its maximum value $\left(r^{2}=0.50\right)$ (Fig. 4). The haplotype analysis showed that 107081 SNPs were grouped into 8720 haplotype blocks. The size of the blocks ranged from $58 \mathrm{bp}$ to $1000 \mathrm{~kb}$ across the whole genome. The distribution of haplotype blocks is shown in table S3.

\section{GWAS analysis for 100SW, PRC and OIC using SNPs via MLM}

Genome-wide association studies were conducted using the best linear unbiased predictors (BLUPS) of individual performance in four environments. A total of 28 SNP loci for 100SW, 198 loci for PRC, and 250 loci for OIC were identified in the mixed linear model (MLM) association panel at suggestive significance level $\left(P=1 \times 10^{-4}\right)$. Among them, the two loci (Gm11_9895764 and Gm11_9917646) controlling 100SW were simultaneously detected in three environments, 9 loci in two environments. Two loci controlling PRC and six loci controlling OIC were simultaneously detected in two environments, respectively. Other loci were only detected in one environment (Fig. 5, Table S4).

The haplotype analysis showed that 10 SNPs were grouped into 5697 haplotype blocks. The size of the blocks ranged from $6 \mathrm{bp}$ to $200 \mathrm{~kb}$ across the whole genome. The distribution of haplotype blocks is 
shown in Supplementary Fig. S3. The haplotype analysis showed that the mapping results were classified into 13 blocks controlling 100SW, 35 blocks controlling RPC and 60 blocks controlling OIC, respectively. Thereinto, the block Gm11_9895764-9917646 controlling 100SW was simultaneously detected in four environments, and two blocks Gm14_46067605-46114908 and Gm14_4865666948766017 were simultaneously detected in two environments. The block Gm20_32208295-33208205 controlling PRC was simultaneously detected in three environments, and the block Gm01_1554929157332 was simultaneously detected in FY2016 and ZG2016. The block Gm20_31492271-32206162 controlling was simultaneously detected in three environments. Four blocks (Gm13_28317040-28337047, Gm18_56604855-56608672, Gm20_26429128-27429119 and Gm20_32208295-33208205) were simultaneously detected in two environments. Other blocks were only detected in one environment. The block (Gm14_48656669-48766017) was detected to control both 100SW and PRC. Three blocks were detected to control both PRC and OIC, as follows: Gm13_28856666-28922456, Gm20_3149227132206162 and Gm20_32208295- 33208205 (Table S4).

\section{Prediction of Candidate Genes}

To predict candidate genes for loci significantly associated with 100SW, PRC and OIC, we selected the putative genes tagged by the most likely reliable blocks. There are 15 putative genes in the range of $50 \mathrm{~kb}$ upstream and downstream of the Gm11_9895764-9917646 block associated with 100SW. Among them, the gene of Glyma.11g130800 encodes transducin/ WD40 repeat-like superfamily protein which regulate seed weight and volume in Arabidopsis thaliana (You, et al., 2011). The gene of Glyma.11g130800 is considered to be the most likely gene for $100 \mathrm{SW}$. There are 17 putative genes in the range of $50 \mathrm{~kb}$ upstream and downstream of Gm13_32352799-32393061 block associated with PRC. The gene of Glyma.13g217000 encodes CCCH-type zinc finger protein which regulates the seed storage protein (Chen et al., 2013). There are 15 putative genes in the range of $50 \mathrm{~kb}$ of the Gm08_9426150 SNP associated with OIC. Among them, the gene of Glyma.08g122600 encodes Aldo-keto reductase which is one of the most important enzymes in fatty acid synthesis. There are 29 putative genes in the block of Gm20_32208295-33208205 for OIC. Among them, the gene of Glyma.20g086700 encodes MATH domain-containing protein which regulates seed oil content (Lassner et al., 1995).

\section{Discussion}

\section{Reliable blocks/loci analysis for 100SW, PRC and OIC in the SCLBP population combing SSR and SNP methods}

The reliable regions were the same or near blocks/loci which were simultaneously detected using SSR and SNPs in multiple environments. The reliable region (Sat_272/ Gm11_9895764-9917646) controlling 100 SW was simultaneously detected using two methods (SSR and SNPs) in FY2018. Five reliable regions controlling PRC were simultaneously detected using two methods in the same environment, as follows: Sat_330/ Gm07_39004283-39052483 in FY2016, BE806308/ Gm11_4433002- 4440881 in ZG2019, Sat_154/ Gm13_32352799-32393061 in ZG2016, Sat_228/ Gm16_6126972-6153823 in ZG2019, 
Sat_260/ Gm18_56464279-56467588 in ZG2019. Seven reliable regions controlling OIC were simultaneously detected using two methods in the same environment, as follows: Satt507/ Gm01_51628454- 51645605 in ZG2019, Sat_137/ Gm05_432661-512958 in ZG2019هSatt424/ Gm08_ 9426150 in ZG2016 and ZG2019هSatt178/ Gm09_7186099 -7230897 in ZG2019, Satt638/ Gm11_5181399-5207087 in FY2018, Satt186/ Gm17_ 40101999-40126120 in FY2018, Sat_170/ Gm20_32208295-33208205 in FY2018 and ZG2016. The regions were considered to be the most likely reliable regions in multiple environments at the same time by two methods. The most likely reliable regions were Gm11_9895764-9917646 for 100SW, Gm13_32352799-32393061 for PRC and Gm08_ 9426150 and Gm20_32208295-33208205 for OIC, respectively.

\section{Potential applications and features of SCLBP}

The high-density genetic map could identify more recombination events and will increases the accuracy of QTLs mapping. In the study, a high-density genetic map was used, and a total of 159072 SNPs was generated by illumina soybean $200 \mathrm{~K}$ gene chip filter 107081 valid SNP markers after filtration on 20 linkage groups. A major goal of development SCLBP was to map the locations of favorable alleles from landraces that could be useful in soybean improvement. A comprehensive evaluation and utilization of large-scale representative germplasm is important for crop improvement through identification and access to allelic variations affecting the crop phenotype. The SCLBP population has advantage of weight of 100SW, elite high protein and oil content for soybean breeding. Mapping populations were the basis of QTL mapping. In soybean, numerous QTL for kinds of traits have been detected by primary mapping populations such as $F_{2}$ (Maughan et al. 1996), $F_{2: 3}$ (Keim et al. 1990), RILs (Orf et al. 1999; Zhang et al. 2004) and so on. The GWAS has advantage in convenience of group construction and detecting multiple alleles of the same locus, and providing better service for plant breeding. It laid a foundation for marker assisted selection and molecular breeding that the closely linked markers were obtained and the elite allelic variation were dissected using the SCLBP population.

\section{Genetic System of 100SW, PRC and OIC in SCLBP}

The difficulty in QTL studies is finding stable and real QTLs that can be detected in various environments and plant materials. With the help of soybean genome (www.soybase.org), the QTL was detected in different populations could be compared. At least $29 \llbracket 31$ and 58 associated with 100 SW, PRC and OIC have been reported in near or the same regions by previous literatures using SSR in the study, respectively (Table S1). At least 11, 44 and 101 for 100SW, PRC and OIC have been reported in near or the same regions by previous literatures using SNP in the study, respectively (Table S4). However, the 9,11 and 9 loci for 100SW, PRC and OIC haven't been reported using SSR. The 3, 5 and 8 for 100SW, PRC and OIC haven't been reported using SNP in the study, respectively. These loci may be novel discovered loci controlling 100sw, PRC and OIC. Broader genetic variation for 100SW, PRC and OIC exists in different soybean populations due to natural and artificial selection in different environments. Further study should confirm these loci and identify candidate genes for them. 


\section{Declarations}

\section{Acknowledgments}

This work was supported by the National Key R\&D Program of China (2018YFD0201006), the National Natural Science Foundation of China $(31871711,31601325)$, the Open fund National Key Laboratory for Crop Genetics and Germplasm Enhancement (ZW201812), the Anhui Provincial College Program for Natural Science (KJ2019A0812), the Science and Technology Program of Sichuan Province (19YYJC0371, 2019YJ0679, 2017NZZJ020, SCCXTD-2020-20).

\section{References}

Akond M., Liu S., Boney M., Kantartzi S., Meksem K., Bellaloui N., Lightfoot D., Kassem M. (2014) Identification of quantitative trait loci (QTL) underlying protein, oil, and five major fatty acids' contents in soybean. American Journal of Plant Sciences 5:158-167.

Bradbury P.J., Zhang Z., Kroon D.E., Casstevens T.M., Ramdoss Y., Buckler E.S. (2007) TASSEL: Software for association mapping of complex traits in diverse samples. Bioinformatics 23:2633-2635.

Burton J.W., Brim C.A., Young M.F. (1987a) Registration of young soybean. Crop Sci., 27:1093.

Burton JW. (1987b) Quantitative genetics: results relevant to soybean breeding. Agronomy 16:211-247.

Chang F.G., Guo C.Y., Sun F.L., Zhang J.S., Wang Z.L., Kong J.J., He Q.Y., Sharmin R.A., Zhao T.J. (2018) Genome-wide association studies for dynamic plant height and number of nodes on the main stem in summer sowing soybeans. Front in Plant Sci. 9:doi: 10.3389/fpls.2018.01184

Chen Y., Sun A.J., Wang M., Zhu Z., Ouwerkerk P.B.F. (2014) Functions of the CCCH type zinc finger protein OsGZF1 in regulation of the seed storage protein GluB-1 from rice. Plant Molecular Biology 84:621-634.

Diers B.W., Keim P., Shoemaker R.C., Fehr W.R. (1992) RFLP analysis of soybean seed protein and oil content. Theor. Appl. Genet. 83(5):608-612.

Doyle J.J., Doyle J.L. (1990) Isolation of plant DNA from fresh tissue. Focus 12: 13-15.

Evanno G., Regnaut S., Goudet J. (2005) Detecting the number of clusters of individuals using the software STRUCTURE: a simulation study. Mol. Ecol. 14:2611-2620.

Falke K.C., Maurer H.P., Melchinger A.E., Piepho H., Flachenecker C., Frisch M. (2007) Linkage disequilibrium in two European $\mathrm{F}_{2}$ flint maize populations under modified recurrent full-sib selection. Theor. Appl. Genet. 115(2): 289-97.

Farnir F., Coppieters W., Arranz J.J., Berzi P., Cambisano N., Grisart B., Karim L., Marcq F., Moreau L., Mni M., Nezer C., Simon P., Vanmanshoven P., Wagenaar D., Georges M. (2000) Extensive genome-wide 
linkage disequilibrium in cattle. Genome Res. 10:220-227.

Fasoula V.A., Harris D.K., Boerma H.R. (2004) Validation and designation of quantitative trait loci for seed protein, seed oil, and seed weight from two soybean populations. Crop Sci. 44:1218-1225.

Fulgione A., Hancock A.M. (2018) Archaic lineages broaden our view on the history of Arabidopsis thaliana New Phytol. 219(4):1194-1198.

Gaut B.S., Long A.D. (2003) The lowdown on linkage disequilibrium. Plant Cell 15(7):1502-1506.

Gupta P.K., Rustgi S., Kulwal P.L. (2005) Linkage disequilibrium and association studies in higher plants: present status and future prospects. Plant Molecular Biology 57:461-485.

Han Y.P., Li D.M., Zhu D., Li H.Y., Li Y.P., Teng W.L., Li W.B. (2012) QTL analysis of soybean seed weight across multi-genetic backgrounds and environments. Theor. Appl. Genet. 125(4):671-683.

He Q.Y., Yang H.Y., Xiang S.H., Tian D., Wang W.B., Zhao T.J., Gai J.Y. (2015) Fine mapping of the genetic locus $\angle 1$ conferring black bods using a chromosome segment substitution line population of soybean. Plant Breeding 134:437-445.

Huang X., Wei X., Sang T., Zhao Q., Feng Q., Zhao Y., Li C., Zhu C., Lu T., Zhang Z., Li M., Fan D., Guo Y., Wang A., Wang L., Deng L., Li W., Lu Y., Weng Q., Liu K., Huang T., Zhou T., Jing Y., Li W., Lin Z., Buckler E.S., Qian Q., Zhang Q.F., Li J., Han B. (2010) Genome-wide association studies of 14 agronomic traits in rice landraces. Nature Genetics 42:961-967.

Illumina (2012) Evalution of infinium genotyping assay controls training guide. San Diego,CA 92122 USA.

Jiang D.K., Sun J.L., Cao G.W., Liu Y., Lin D.X., Gao Y.Z., Ren W.H., Long X.D., Zhang H.X., Ma X.P., Wang Z., Jiang W., Chen T.Y., Gao Y., Sun L.D., Long J.R., Huang H.X., Wang D., Yu H.J., Zhang P.Y., Tang L.S., Peng B., Cai H., Liu T.T., Zhou P., Liu F., Lin XL., Tao S., Wan B., Yin HXGS., Qin LX., Yin JH., Liu L., Wu C., Pei Y., Zhou Y.F., Zhai Y., Lu P.X., Tan A.H., Zuo X.B., Fan J., Chang J., Gu X.L., Wang N.J., Li Y., Liu Y.K., Zhai K., Zhang H.W., Hu Z.B., Liu J., Yi Q., Xiang Y.B., Shi R., Ding Q., Zheng W., Shu X.O., Mo Z.N., Shugart Y.Y., Zhang X.J., Zhou G.Q., Shen H.B., Zheng S.L., Xu J.F., Yu L. (2013) Genetic variants in STAT4 and HLA-DQ genes confer risk of hepatitis B virus-related hepatocellular carcinoma. Nature Genetic 45:72-75.

Jun T., Van K., Kim M., Lee S., Walker D. (2008) Association analysis using SSR markers to find QTL for seed protein content in soybean. Euphytica 162(2):179-191.

Keim P., Diers B.W., Olson T.C., Shoemaker R.C. (1990) RFLP mapping in soybean: association between marker loci and variation in quantitative traits. Genetics 126 (3):735-742.

Kim S., Plagnol V., Hu T.T., Toomajian C., Clark R.M., Ossowski S., Ecker J.R., Weigel D., Nordborg M. (2007) Recombination and linkage disequilibrium in Arabidopsisthaliana. Nat. Genet. 39(9):1151-1155. 
Lassner M.W., Levering C.K., Davies H.M., Knutzon D.S. (1995) Lysophosphatidic acid acyltransferase from meadowfoam mediates insertion of erucic acid at the sn-2 position of triacylglycerol in transgenic rapeseed oil. Plant physiology 109(4):1389-1394.

Li C., Dong Y., Zhao T., Li L., Li C., Yu E., Mei L., Daud M.K., He Q., Chen J., Zhu S. (2016) Genome-wide SNP linkage mapping and QTL analysis for fiber quality and yield traits in the upland cotton recombinant inbred lines population. Front Plant Sci. 7:doi: 10.3389/fpls.2016.01356.

Li X.H., Shao Z.Q., Tian R., Zhang H., Du H., Kong Y.B., Li W.L., Zhang C.Y. (2019) Mining QTLs and candidate genes for seed protein and oil contents across multiple environments and backgrounds in soybean. Mol. Breeding 39(11):139. doi.org/10.1007/s11032-019-1055-7.

Liu R., Gong J., Xiao X., Zhang Z., Li J., Liu A., Lu Q., Shang H., Shi Y., Ge Q., Iqbal M.S., Deng X., Li S., Pan J., Duan L., Zhang Q., Jiang X., Zou X., Hafeez A., Chen Q., Geng H., Gong W., Yuan Y. (2018) GWAS analysis and QTL identification of fiber quality traits and yield components in upland cotton using enriched high-density SNP markers. Front in Plant Sci. 9:doi:10.3389/fpls. 2018.01067

Lu X., Xiong Q., Cheng T., Li Q.T., Liu XL., Bi Y.D., Li W., Zhang W.K., Ma B., Lai Y.C. (2017) A PP2C-1 allele underlying a quantitative trait locus enhances soybean 100-seed weight. Mol. Plant 10(5):670-84.

Mansur L.M., Orf J.H., Chase K., Jarvik T., Cregan P.B., Lark K.G. (1996) Genetic mapping of agronomic traits using recombinant inbred lines of soybean. Crop Sci. 36(5):1327-1336.

Maughan P.J., Maroof M.A.S., Buss G.R. (1996) Molecular-marker analysis of seed-weight: genomic locations, gene action, and evidence for orthologous evolution among three legume species. Theor. Appl. Genet. 93 (4):574-579.

McMullen M.D., Kresovich S., Villeda H.S., Bradbury P., Li H., Sun Q., Flint-Garcia S., Thornsberry J., Acharya C., Bottoms C., Brown P., Browne C., Eller M., Guill K., Harjes C., Kroon D., Lepak N., Mitchell S.E., Peterson B., Pressoir G., Romero S., Oropeza Rosas M., Salvo S., Yates H., Hanson M., Jones E., Smith S., Glaubitz J.C., Goodman M., Ware D., Holland J.B., Buckler E.S. (2009) Genetic properties of the maize nested association mapping population [J]. Science 325(5941):737-40.

Miller J.M., Poissant J., Malenfant R.M., Hogg J.T., Coltman D.W. (2015) Temporal dynamics of linkage disequilibrium in two populations of bighorn sheep. Ecol. Evol. 5(16):3401-3412.

Orf J.H., Chase K., Jarvik T., Mansur L.M., Cregan P.B., Adler F.R., Lark K.G. (1999) Genetics of soybean agronomic traits: I. comparison of three related recombinant inbred populations. Crop Sci. 39 (6):16521656.

Pritchard J.K., Przeworkski M. (2001) Linkage disequilibrium in humans: models and data. Am. J. Hum. Genet. 69:1-14. 
Pritchard J.K., Stephens M., Donnelly P. (2000) Inference of population structure using multilocus genotype data. Genetics 155(2):945-959.

Rossi M., Orf J., Liu L., Dong Z., Rajcan I. (2013) Genetic basis of soybean adaptation to North American vs. Asian mega-environments in two independent populations from Canadian $\mathrm{x}$ Chinese crosses. Theor. Appl. Genet. 126(7): 1809-1823.

Shaun P. (2010) PLINK (1.07) documentation. Center for Human Genetic Research.

Shin J.H., Blay S., McNeney B., Graham J. (2006) LD heatmap: an R function for graphical display of pairwise linkage disequilibria between single nucleotide polymorphisms. Journal of Statistical Software 16:1-9.

Specht J.E., Chase K., Macrander M., Graef G.L., Chung J., Markwell J.P., Germann M., Orf J.H., Lark K.G. (2001) Soybean response to water: a QTL analysis of drought tolerance. Crop Sci. 41(2):493-509.

Song Q.J., Marek L.F., Shoemaker R.C., Lark K.G., Concibido V.C., Delannay X., Specht J.E., Cregan P.B. (2004) A new integrated genetic linkage map of the soybean. Theor. Appl. Genet. 109:122-128.

Tang Y., Liu X.L., Wang J.B., Li M., Wang Q.S., Tian F., Su Z.B., Pan Y.C., Liu D., Lipka A.E., Buckler E.S., Zhang Z.W. (2016) GAPIT Version 2: An enhanced integrated tool for genomic association and prediction. The Plant Genome 9 (2):1-9.

Wang X.Z., Jiang G.L., Gree M., Scott R.A., Song Q.J., Hyten D.L., Cregan P.B. (2014) Identification and validation of quantitative trait loci for seed yield, oil and protein contents in two recombinant inbred line populations of soybean. Mol. Genet. Genomics 289:935-949.

Yang H.Y., Wang W.B., He Q.Y., Xiang S.H., Tian D., Zhao T.J., Gai J.Y. (2019) Identifying a wild allele conferring small seed size, high protein content and low oil content using chromosome segment substitution lines in soybean. Theor. Appl. Genet. 132(6):2793-2807.

Yang W., Guo Z., Huang C., Duan L., Chen G., Jiang N., Fang W., Feng H., Xie W., Lian X., Wang G., Luo Q., Zhang Q., Liu Q., Xiong L. (2014) Combining high-throughput phenotyping and genome-wide association studies to reveal natural genetic variation in rice. Nat. Commun. 5: doi: 10.1038/ncomms6087.

Yang W., Guo Z., Huang C., Wang K., Jiang N., Feng H., Chen G., Liu Q., Xiong L. (2015) Genome-wide association study of rice (Oryza sativa L.) leaf traits with a high-throughput leaf scorer. J. Exp. Bot. 66(18):5605-5615.

Yang Z.L., Zhou X.A. (2020) Breeding advance of high protein soybean in China. Hefei: Conference of promotion of soybean industry chain in Anhui.

You X.H., Li W., Tao Q.C., Sun X.F., Tang K.X. (2011) At1g65030, a WD40-repeat protein gene, regulates seed mass and size in Arabidopsis. Plant Physiology Journal 47(7):715-725. 
Zhang J.P., Song Q.J., Cregan P.B., Nelson R.L., Wang X.Z., Wu J.X., Jiang G.L. (2015) Genome-wide association study for flowering time, maturity dates and plant height in early maturing soybean (Glycine max) germplasm. BMC Genomics 16: doi: 10.1186/s12864-015-1441-4.

Zhang W.K., Wang Y.J., Luo G.Z., Zhang J.S., He C.Y., Wu X.L., Gai J.Y., Chen S.Y. (2004) QTL mapping of ten agronomic traits on the soybean (Glycine max L. Merr.) genetic map and their association with EST markers. Theor. Appl. Genet. 108 (6):1131-1139.

\section{Tables}

Table 1 Descriptive statistics, genetic variation of 100SW, PRC and OIC under four environments

\begin{tabular}{|c|c|c|c|c|c|c|c|}
\hline Trait & Environment & Means $\pm S D$ & Range & Skewness & Kurtosis & GCV $(\%)$ & $h^{2}(\%)$ \\
\hline \multirow[t]{4}{*}{ 100SW } & FY2016 & $14.55 \pm 4.36$ & $7.87 \rrbracket 31.55$ & 0.80 & 0.68 & 26.85 & 77.01 \\
\hline & FY2018 & $13.27 \pm 4.48$ & $4.82 \rrbracket 27.13$ & 0.68 & 0.14 & 32.15 & 84.82 \\
\hline & ZG2016 & $13.94 \pm 4.78$ & $6.43 \rrbracket 33.35$ & 1.12 & 1.58 & 32.35 & 97.02 \\
\hline & ZG2019 & $15.37 \pm 4.45$ & $6.65 \rrbracket 27.90$ & 0.52 & -0.20 & 28.65 & 95.58 \\
\hline \multirow[t]{4}{*}{ PRC } & FY2016 & $44.46 \pm 1.69$ & $39.79 \llbracket 49.75$ & -0.11 & 0.14 & 2.75 & 43.86 \\
\hline & FY2018 & $44.86 \pm 1.91$ & $40.47 \rrbracket 49.71$ & 0.24 & -0.42 & 3.70 & 63.19 \\
\hline & ZG2016 & $40.80 \pm 1.51$ & $37.15 \llbracket 44.73$ & 0.23 & -0.26 & 3.28 & 83.34 \\
\hline & ZG2019 & $40.92 \pm 1.59$ & $36.47 \rrbracket 44.70$ & 0.06 & -0.34 & 3.45 & 64.99 \\
\hline \multirow[t]{4}{*}{ OIC } & FY2016 & $18.46 \pm 1.16$ & $15.62 \llbracket 21.77$ & 0.13 & 0.10 & 4.61 & 47.21 \\
\hline & FY2018 & $18.15 \pm 137$ & $14.68 \llbracket 21.70$ & -0.16 & -0.42 & 6.63 & 66.56 \\
\hline & ZG2016 & $18.39 \pm 1.02$ & $14.72 \llbracket 20.72$ & -0.47 & 0.36 & 5.03 & 89.17 \\
\hline & ZG2019 & $17.88 \pm 1.03$ & $14.78 \llbracket 20.89$ & -0.05 & 0.33 & 5.40 & 77.80 \\
\hline
\end{tabular}




\begin{tabular}{|lllllll|}
\hline Traits & Source & Df & Type III SS & Mean Square & FValue & Pr $>F$ \\
\hline \multirow{3}{*}{ 100SW } & Varieties & 227 & 35491.14 & 156.35 & 57.33 & 0.000 \\
\cline { 2 - 7 } & Environments & 3 & 1152.85 & 384.29 & 140.91 & 0.000 \\
\cline { 2 - 7 } & Varieties $\times$ Environments & 673 & 5693.34 & 8.46 & 3.10 & 0.000 \\
\hline \multirow{2}{*}{ PRC } & Varieties & 227 & 3276.36 & 14.43 & 8.47 & 0.000 \\
\cline { 2 - 7 } & Environments & 3 & 7417.56 & 2472.52 & 1450.10 & 0.000 \\
\cline { 2 - 7 } & Varieties $\times$ Environments & 673 & 2501.05 & 3.72 & 2.18 & 0.000 \\
\hline \multirow{2}{*}{ OIC } & Varieties & 227 & 1706.24 & 7.52 & 11.63 & 0.000 \\
\cline { 2 - 7 } & Environments & 3 & 101.59 & 33.86 & 52.39 & 0.000 \\
\cline { 2 - 7 } & Varieties $\times$ Environments & 673 & 965.50 & 1.44 & 2.22 & 0.000 \\
\hline
\end{tabular}

Figures
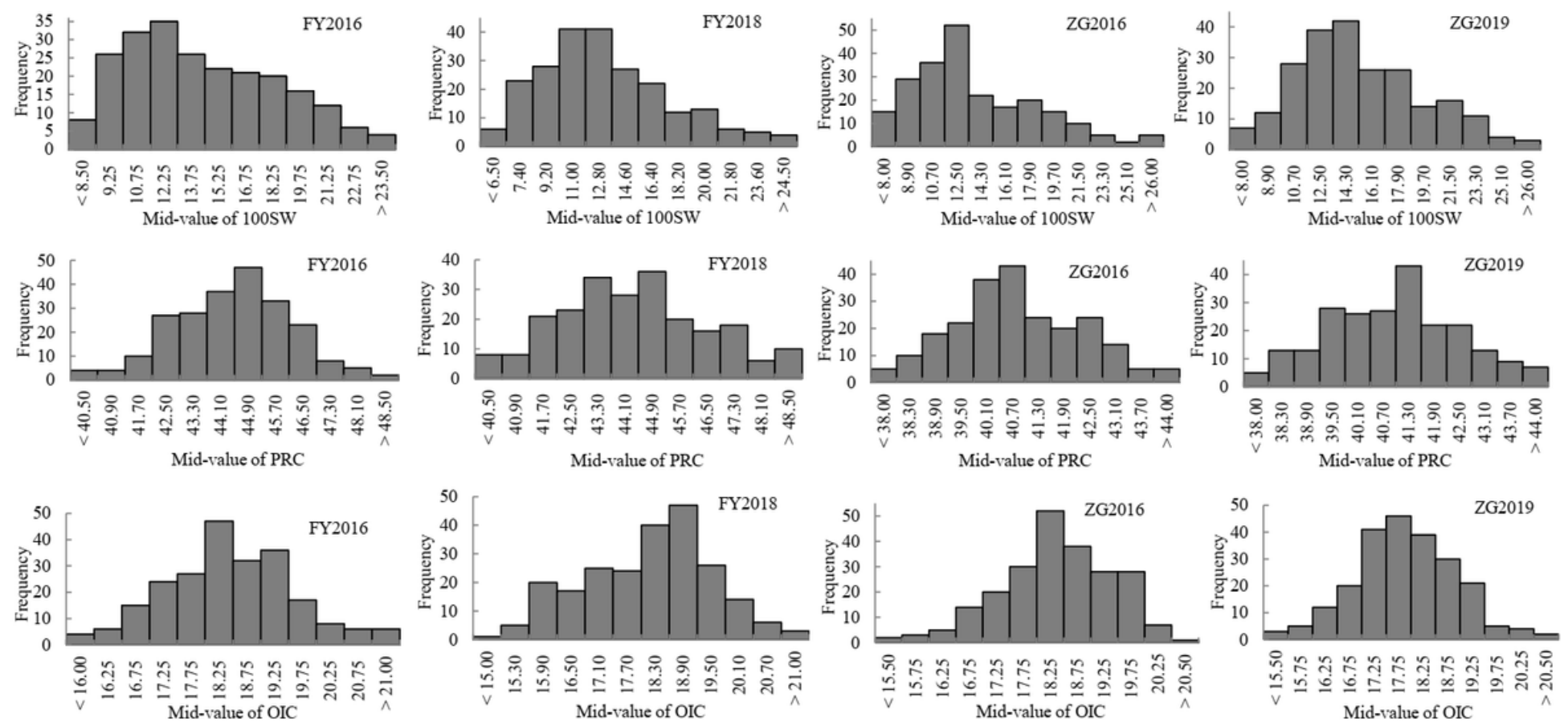

\section{Figure 1}

Distribution of 100SW, PRC and OIC under four environments 


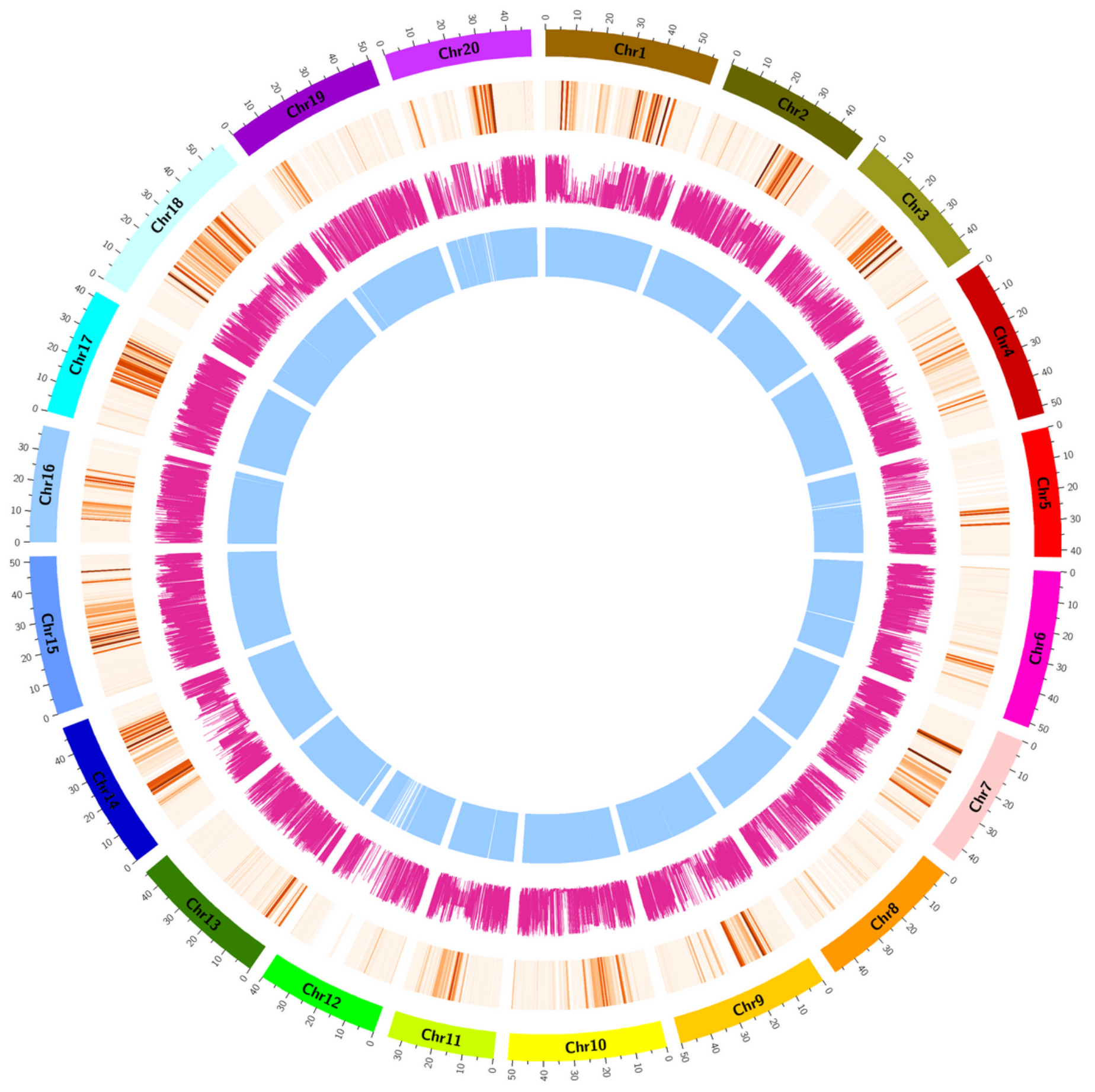

Figure 2

Characterization of the SNPs in the soybean genome. Note: The distribution of chromosomes, blocks, MAF and SNP was from outside to inside 

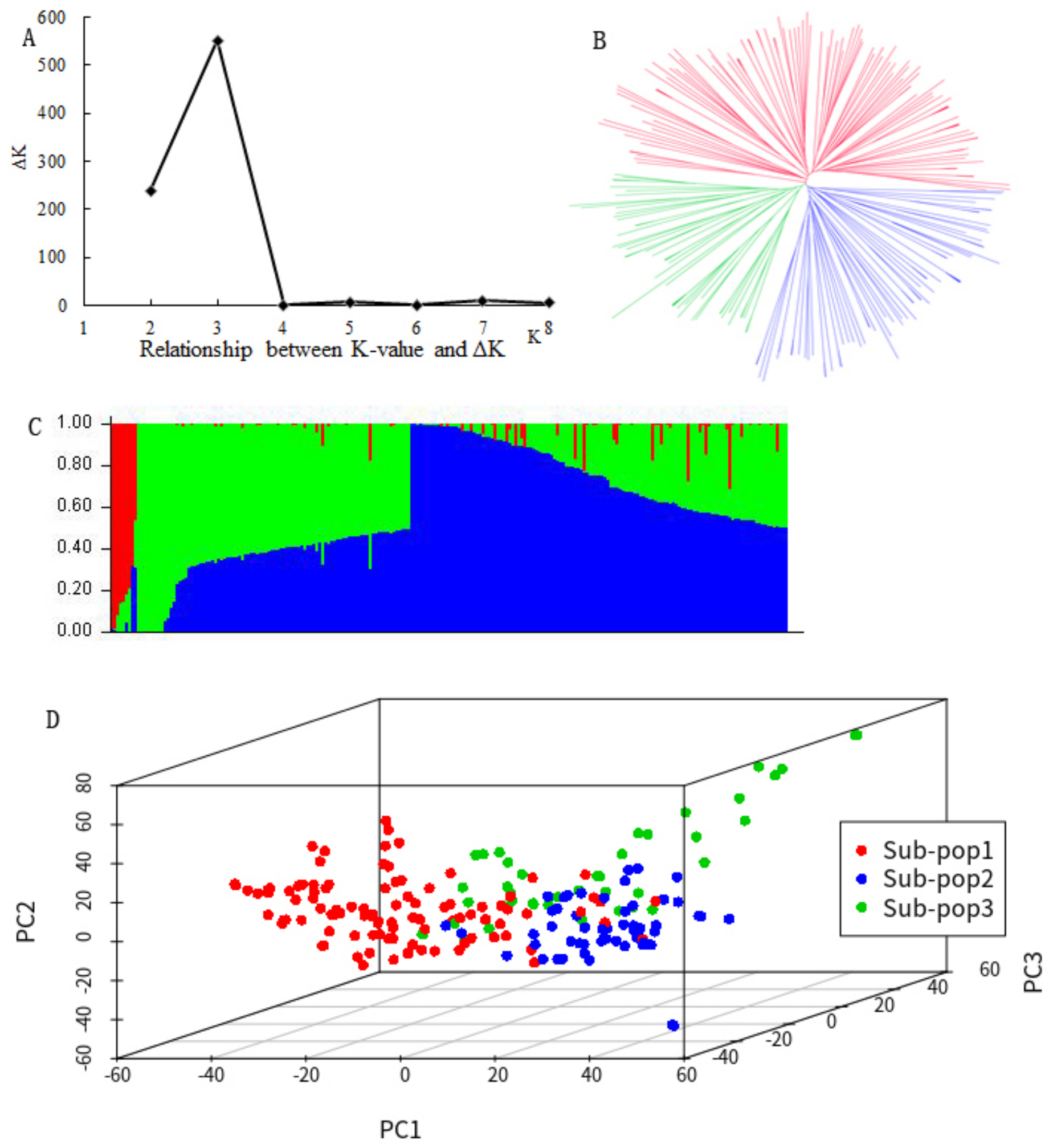

\section{Figure 3}

Population structure of 228 soybean accessions Note: (A) Calculation of the true K of the SCLBP. (B) A neighbor-joining tree of the tested accessions that could be divided into three subpopulations. (C) Population structure was estimated by Structure. Three colors represent three subpopulations, respectively. Each vertical column represents one individual and each colored segment in each column 
represents the percentage of the individual in the population. (D) PCA plot of the 228 accessions; threedimensional scales were used to reveal population stratification.

A

LD decay

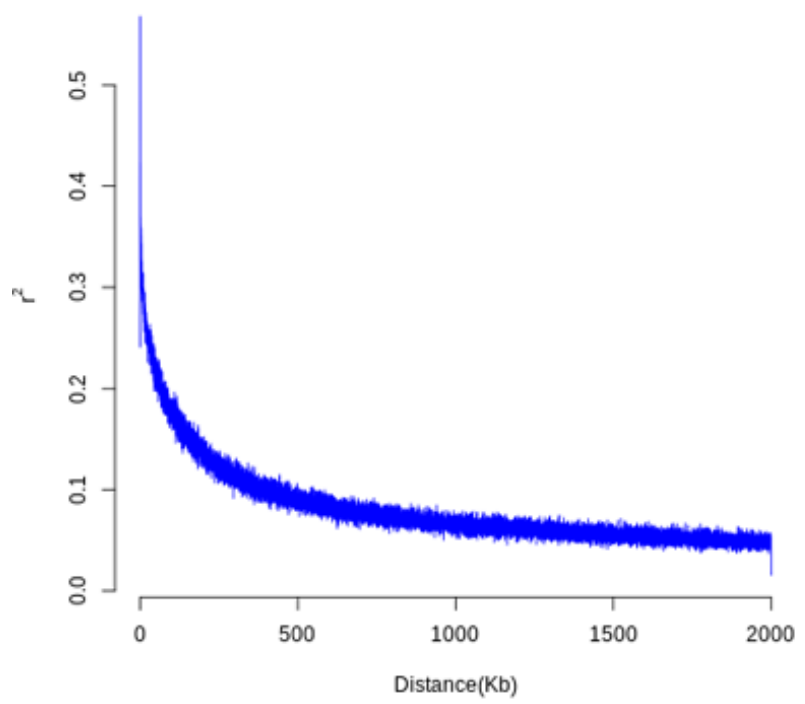

B

$10 s 41786669$ 10541822297

$10 s 41840400$ $10 s 41852895$ $10 s 41867187$ $10 s 41886088$ $10 s 41899741$ 10541928420 $10 s 41935113$ 10541984963 10542016458 $10 s 42077455$ 10542086460 10542093038 $10 \leq 42134992$ $10 s 42144203$ $10 s 42151018$ $10 s 42157572$ $10 s 42160511$ 10542167597 10542178036 $10 \leq 42185728$ $10 s 42188657$ $10 s 42215447$ 10542218198 $10 \leq 42222333$ 10542224608 $10 s 42240985$ $10 \leq 42253414$ $10 \leq 42255150$ 10542272334 $10 s 42277415$ 10542283516 $10 s 42289144$ 10542290519

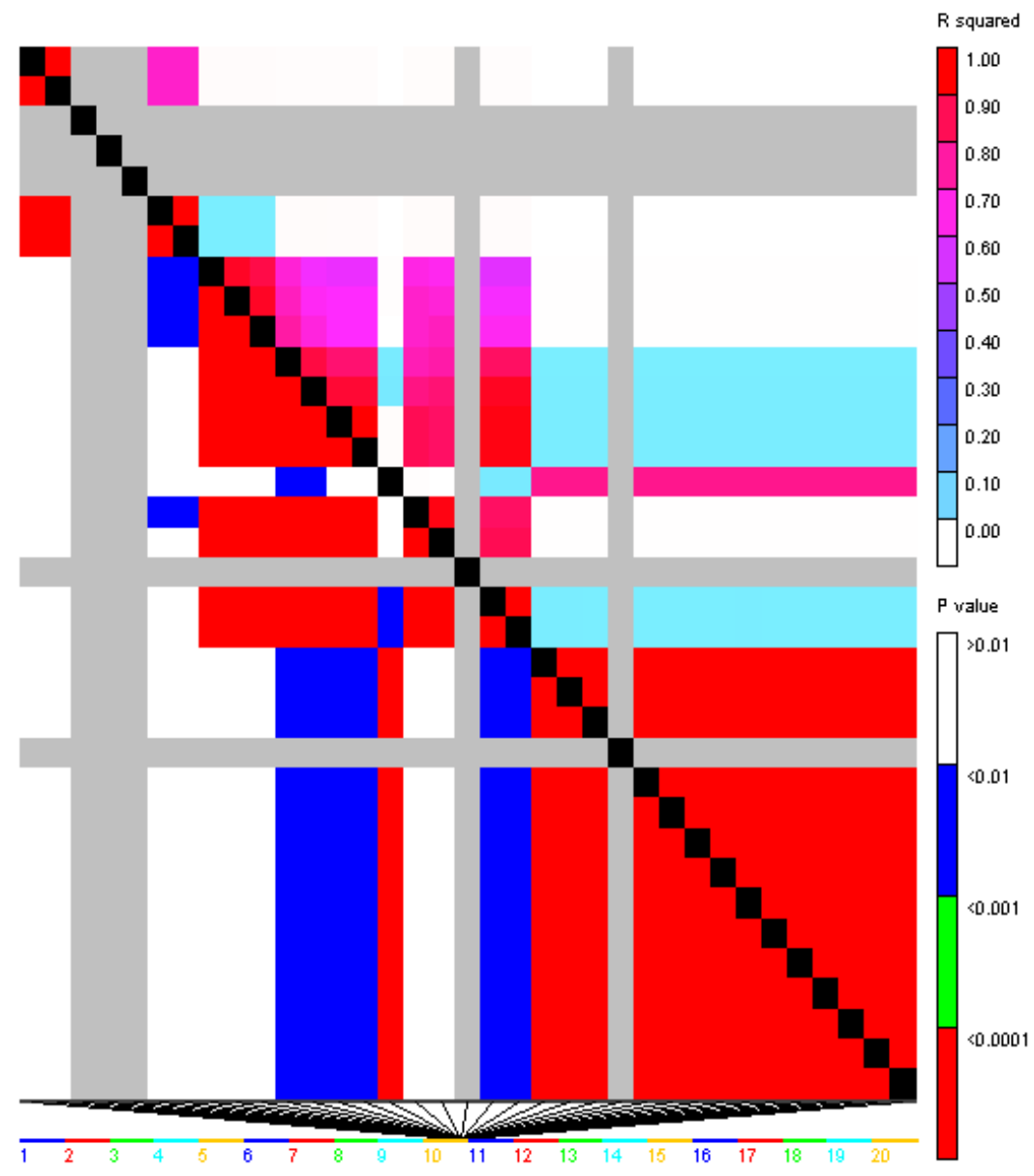

Figure 4

LD decay and genomic association of 228 soybean accessions Note: (A) LD decay (B) Linkage disequilibrium in genome 


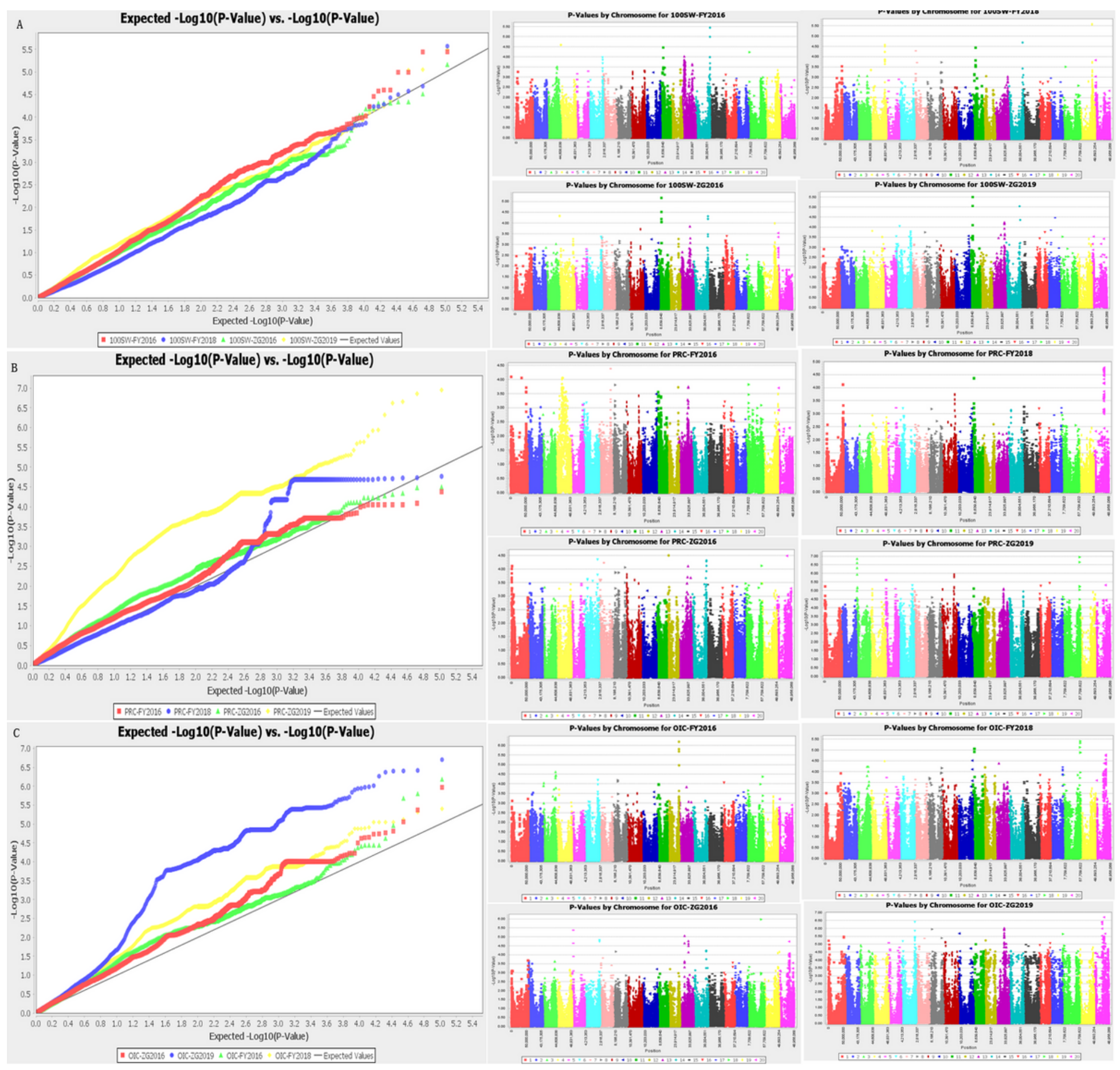

Figure 5

Quantile-quantile plots and Manhattan for 100SW, PRC and OIC in four environments (A) 100SW (B) PCR (C) OIC

\section{Supplementary Files}

This is a list of supplementary files associated with this preprint. Click to download.

- SupplementS1Referencescomparsions.docx 
- TableS2107081validSNPs.xIsx

- TableS3BlockofSNPs.xlsx

- TableS4SNPMLMBlock.xlsx 